\title{
RAGAM BAHASA GAUL DALAM MEDIA SOSIAL FACEBOOK REMAJA NEGERI PASSO KOTA AMBON
}

\author{
Inggrid Akyuwen \\ Carolina Sasabone \\ Novita Tabelessy \\ Universitas Pattimura \\ e-mail: inggridakyuwen12@gmail.com
}

\begin{abstract}
Abstrak: Tujuan penelitian yang ingin dicapai dalam penelitian ini adalah mendeskripsikan ragam bahasa gaul dalam media sosial facebook remaja di Negeri Passo Kota Ambon. jenis penelitian yang digunakan adalah penelitian deskriptif kualitatif. Pendekatan kualitatif yang menggunakan manusia sebagai instrument penelitian. Hasil penelitian yang ditemukan yaitu bentuk dan makna pemakaian ragam bahasa gaul dalam tuturan remaja di media sosial facebook khususnya remaja Negeri Passo, Kota Ambon yang dapat diklasifikasikan berdasarkan, (a) bentuk jargon, (b) bentuk prokem, (c) bentuk colloquial.
\end{abstract}

Kata Kunci: Ragam bahasa gaul, media sosial facebook, remaja Negeri Passo, Kota Ambon 


\title{
TEEN'S VARIETY OF SLANG ON SOCIAL MEDIA FACEBOOK IN PASSO VILLAGE AMBON CITY
}

\author{
Inggrid Akyuwen \\ Carolina Sasabone \\ Novita Tabelessy \\ Universitas Pattimura \\ e-mail: inggridakyuwen12@gmail.com
}

\begin{abstract}
The research objective to be achieved in this study is to describe the variation of slang in social media Facebook teenagers in village Passo Ambon City.the type of research used is descriptive qualitative research. A qualitative approach that uses humans as research instruments. The results of the study found are the forms and meanings of the use of various slang languages in teen conversation on Facebook especially teenagers in Passo, Ambon City which can be classified based on, (a) jargon forms, (b) prokem forms, (c) colloqial forms
\end{abstract}

Keywords: various slang languages, Facebook social media, Passo teenagers, Ambon City. 


\section{A. PENDAHULUAN}

Bahasa adalah alat komunikasi dan interaksi yang hanya dimiliki manusia, yang dapat dikaji internal maupun eksternal. Pengkajian secara internal, dilakukan terhadap struktur intern bahasa seperti struktur fonologisnya, struktur morfologisnya, atau struktur sintaksisnya. Kajian internal ini akan menghasilkan perian-perian bahasa tanpa ada kaitannya dengan masalah lain di luar bahasa. Sebaliknya, kajian secara eksternal, berarti, kajian itu dilakukan terhadap hal-hal atau faktor-faktor yang berada di luar bahasa yang berkaitan dengan pemakain bahasa itu oleh para penuturnya di dalam kelompok-kelompok sosial kemasyarakaratan (Abdul Chaer, 2010:1).

Adapun keragaman atau variasi bahasa bukan hanya disebabkan oleh penutur yang tidak homogen, melainkan juga karena interaksi sosial yang beragam. Setiap kegiatan memerlukan atau menyebabkan terjadinya keragaman bahasa itu sendiri. Salah satu ragam bahasa yang biasa digunakan adalah bahasa gaul. Bahasa adalah sistim lambang bunyi yang arbitrer, yang digunakan oleh anggota suatu masyarakat untuk berinteraksi, dan mengidentifikasi diri sedangkan ragam bahasa yaitu bentuk bahasa yang bervariasi menurut konteks pemakaian, biasanya menguasai berbagai- bagai jenis ragam bahasa yang mampu menyesuaikan ragam yang dipakai dengan situasi dan tujuan berbahasa. Bahasa gaul pada umumnya ragam ini digunakan sebagai sarana komunikasi di antara remaja sekelompoknya selama kurun tertentu. Hal ini dikarenakan, remaja memiliki cara tersendiri dalam mengungkapkan ekspresi diri. Sarana komunikasi diperlukan oleh kalangan remaja untuk menyampaikan hal-hal yang dianggap tertutup bagi kelompok usia lain atau agasr pihak lain tidak dapat mengetahui apa yang sedang dibicarakannya. Masa remaja memiliki karakteristik antara lain petualangan, pengelompokan, dan kenakalan. Ciri ini tercermin juga dalam bahasa mereka. Keinginan untuk membuat kelompok eksklusif menyebabkan mereka menciptakan bahasa rahasia

Kosakata bahasa gaul yang lahir dari lingkungan hidup di kelompok remaja memiiki bentuk dan maknanya sangat beragam tergantung pada pemakainya. Kehadiran bahasa gaul itu dapat dianggap wajar karena sesuai dengan tuntutan perkembangan nurani anak usia remaja. Masa hidupnya terbatas sesuai dengan perkembangan usia remaja. Selain itu, pemakainnya pun terbatas pula di kalangan remaja kelompok usia tertentu, dan bahasa yang digunakan merupakan bahasa yang bersifat tidak resmi, dan kehadiran bahasa gaul di dalam pertumbuhan bahasa Indonesia ataupun bahasa daerah tidak perlu dirisaukan karena bahasa itu masing-masing akan tumbuh dan berkembang sendiri sesuai dengan fungsi dan keperluannya masing-masing.

Fenomena bahasa gaul di kalangan remaja perkembangan di era globalisasi ini yang menuntut anak remaja selalu aktif menciptakan bahasa terbaru (up date) menjadi salah satu penyebab pesatnya bahasa gaul dan berkembangnya teknologi situs di jejaring sosial, seperti facebook dan semakin lama bahasa gaul tersebut terus berkembang dan berganti tren. Kemunculannya dapat dikatakan fenomenal, karena cukup menyita perhatian. Bahasa gaul ini seolah menggeser penggunaan bahasa Indonesia dikalangan segelintir remaja. Sehubungan dengan semakin maraknya penggunaan bahasa gaul yang digunakan oleh kalangan remaja dan sudah terdengar norak di masyarakat luas tapi masih saja digunakan para remaja untuk menulis dijejaring sosial, sehingga perlu adanya tindakan dari semua pihak yang peduli terhadap eksistensi kesantunan berbahasa dari sejak lahir hingga kini, bahasa masih tetap terasa kesulitan untuk berbahasa yang indah dan santun. Modifikasi bahasa dalam 
bahasa gaul ternyata membawa sinyal ancaman serius terhadap bahasa Indonesia terutama dikalangan remaja.

Keragamaan ini akan semakin bertambah kalau bahasa tersebut digunakan oleh penutur yang sangat banyak serta dalam wilayah yang luas, misalnya penggunaan bahasa gaul di kalangan remaja Negeri Passo, Kota Ambon. juga merambat ke dunia maya seperti media sosial terutama facebook, sebagai salah satu media sosial yang paling banyak digunakan di antara media sosial lainnya seperti Contoh bahasa gaul yang sering digunakan oleh remaja di Negeri Passo, Kota Ambon, yaitu: Pelakor (perebut laki orang), jamur (janda muda di bawah umur), bataso (bandel tapi sopan), ambur love( buang cinta), dan masi banyak juga bahasa gaul yang digunakan oleh remaja Negeri Passo, Kota Ambon.

Bahasa gaul sebagai salah satu ragam bahasa yang digunakan di kalangan remaja Negeri Passo Kota Ambon merupakan suatu bahasa yang sangat unik dan khas sehingga peneliti ingin meneliti lebih dalam tentang ragam bahasa gaul yang digunakan oleh remaja Negeri Passo, Kota Ambon dan dicermati dari segi penggunaannya. Oleh karena itu, peneliti ingin mengangkat masalah ini ke dalam bentuk karya tulis skripsi guna memperdalam pemahaman tentang ragam bahasa gaul remaja Negeri Passo, Kota Ambon terutama dalam media sosial facebook.

\section{B. METODE PENELITIAN}

Metode penelitian yang tepat untuk ragam bahasa gaul dalam media sosial facebook remaja Negeri Passo, Kota Ambon adalah metode kualitatif yang bersifat deskriptif. Dengan alasan pendekatan kualitatif merupakan prosedur penelitian yang menghasilkan data deskriptif berupa kata-kata tertulis.

Data penelitian ini adalah data berupa kata tertulis, yang di buat dalam bentuk kalimat bahasa gaul yang dipostingkan oleh remaja di Negeri Passo, Kota Ambon dalam media sosial facebook.

Sumber data dalam penelitian ini adalah kata yang tertulis yang dipostingkan melalui media facebook berupa status dan komentar dari para remaja yang berdomisili di Negeri Passo, Kota Ambon yang berusia antara 14 tahun sampai 19 tahun.

Untuk mengumpulkan data, penulis menggunakan teknik wawancara, pencatatan lapangan, dan dokumentasi

\section{a) Teknik Analisis Data}

Analisis data kualitatif merupakan upaya berlanjut, berulang dan terus menerus. Menurut milles dan huberman (dalam Moleong 1990:15-16) data yang dikumpulkan dalam aneka macam cara proses melalui pencatatan dan pengetikan. Analisis data melalui tiga alur kegiatan yang terjadi secara bersama yaitu :

1. Reduksi data, yaitu proses pemilihan dan pemusatan pada penyederhanaan, pengabstrakan, dan transformasi data yang muncul pada catatan lapangan tertulis di lapangan. Redeksi data merupakan bagian dari analisis data dengan suatu bentuk analisis yang menajamkan, menggolongkan mengarahkan, membuang, data yang tidak diperlukan, dan mengorganisasi data sehingga kesimpulan final diambil 
2. Penyajian data, merupakan alur kedua dalam kegiatan analisi data yaitu kumpulan informasi tentang penelitian yang dilakukan dan memberi kemungkinan adanya penarikan kesimpulan dan pengambilan tindakan.

3. Kesimpulan, merupakan simpulan informasi yang tersusun memungkinkan adanya penarikan kesimpulan dan pengambilan tindakan. Penarikan kesimpulan hanyalah sebagai dari suatukegiatan. Kesimpulan juga diverifekasi selama penelitian berlangsung.

\section{PEMBAHASAN}

Pada bagian ini dipaparkan hasil penelitian yaitu ragam bahasa gaul dalam media sosial facebook remaja Negeri Passo, Kota Ambon. Deskripsi hasil penelitian tersebut disesuaikan dengan tujuan penelitian yaitu mendeskripsikan ragam bahasa gaul dalam media sosial facebook remaja di Negeri Passo Kota Ambon.

Berdasarkan hasil analisis data ditemukan tiga jenis bahasa gaul yaitu, bahasa gaul jargon, bahasa gaul prokem, dan bahasa gaul colloquial. Ragam bahasa gaul tersebut antara lain yaitu:

\section{Bahasa Gaul Jenis Jargon}

Jargon merupakan ungkapan atau ekspresi yang dapat berupa kata yang dipopulerkan oleh orang terkenal melalui media televisi, bioskop, majalah , radio, atau sebuah potongan lirik lagu. Kosakata bentuk jargon terdapat dalam media sosial fecebook remaja Negeri Passo, Kota Ambon. Adapun data yang diperoleh dalam bentuk sisipan, singkatan, dan akronim seperti berikut:

Data 01:

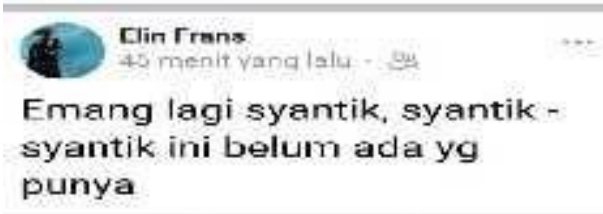

- memang lagi cantik. Cantik-cantik ini belum ada yang punya.

Kata syantik mulai akrab digunakan dan didengar saat populer lagu yang dinyanyikan oleh Siti Badriah dengan judul lagi syantik. Lirik ini berarti menyatakan bahwa dia merasa dirinya cantik dan kata ini sering digunakan di masyarakat pada kalangan remaja sampai pemuda.

Konteks: Peristiwa tutur yang disampaikan oleh Elin Frans di facebook saat penutur sedang menyampaikan isi hatinya dan merasa dirinya cantik tetapi belum juga mempunyai kekasih.

Makna data jargon 01: Makna kata syantik yang berasal dari kata dasarnya cantik yang di memaknai bahwa seseorang yang terlihat dari wajah dan tubuh yang terlihat indah dan menawan. 


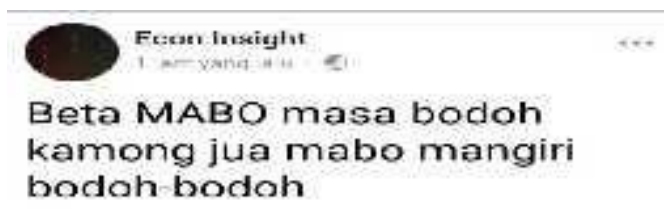

Data 02:

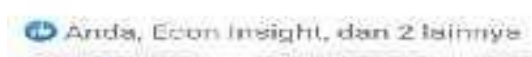

- Saya minum kalian juga minum iri bodoh-bodoh

Pada status tersebut terdapat Kata Mabo yang akronim dari masa bodoh. Kata ini mulai akrab digunakan dan didengar oleh masyarakat Maluku saat populer lagu yang dinyanyikan oleh Roy Sklil dengan judul Beta Mabo. Fungsi kata mabo untuk sapaan buat seorang peminum dan sering digunakan oleh kalangan remaja dan pemuda Negeri Passo.

Konteks: Peristiwa tutur yang disampaikan oleh Econ Insight di facebook saat dia tidak peduli kepada teman- teman yang berbicara mengenai kehidupannya dan merasa iri hati kepadanya.

Makna data jargon 02: Makna kata Mabo yang kita ketahui dalam masyarakat Maluku adalah seseorang peminum minuman keras, tetapi berbeda dengan kata Mabo yang dituturkan oleh penutur yaitu merupakan akronim dari Masa bodoh, yang artinya tidak peduli dengan segala hal tentang perkataan orang lain kepadanya.

\section{Bentuk Bahasa Gaul Prokem}

Prokem adalah suatu bentuk bahasa gaul yang di proses dalam pembentukanya dengan cara, membalikan susunan kata, memberi suatu sisipan, kata-kata yang diambil dengan proses akronim dan singkatan, Perubahan vokal dan konsonan, sehingga bentuk kata asli berubah bunyinya tidak mudah dipahami, dan menjadi aneh, serta terasa asing dan lucu bagi sebagian masyarakat. Kosakata bentuk prokem yang terdapat dalam media sosial facebook remaja Passo, Kota Ambon. Adapun data yang diperoleh dalam bentuk perubahan fonem, penghilangan fonem, singkatan dan akronim sebagai berikut:

Data 01: Merupakan percakapan ketika narasumber mengomentari foto teman facebook-nya 


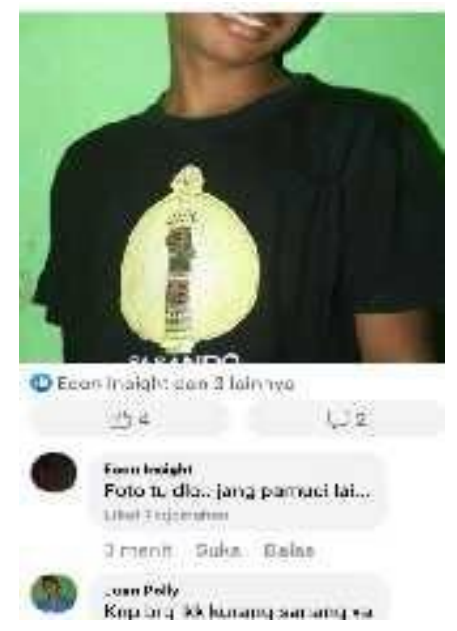

Econ Insight: foto itu jangan pasang muka cinta lagi Juan Polly: kenapa memang kakak kurang senang ya

Pada status tersebut terdapat Kata pamuci yang merupakan akronim dari kalimat pa-(sang $)+m u(k a)+$ ci $(-n t a)$ yang murupakan kependekan dari $\{$ pa $\}$ sebagian suku pertama kata $\{$ pasang $\},\{m u\}$ suku pertama kata $\{$ muka $\}$ dan $\{\mathrm{ci}\}$ gabungan huruf pertama dan kedua dari kata \{cinta\}. Kata ini sering digunakan oleh kalangan remaja dan pemuda Negeri Passo.

Konteks: Peristiwa tutur dalam percakapan komentar yang disampaikan oleh Econ Insight dalam mengomentari foto temannya yang di maksudkan untuk menggangu atau mengejek foto yang dipostingkan oleh temanya.

Makna data prokem 01: Makna kata pamuci digunakan untuk mengartikan cara penampilan atau identik dengan kebiasaan seseorang yang suka bergaya di depan cewek-cewek (gadis) yang dimaknai yaitu " pasang muka cinta"

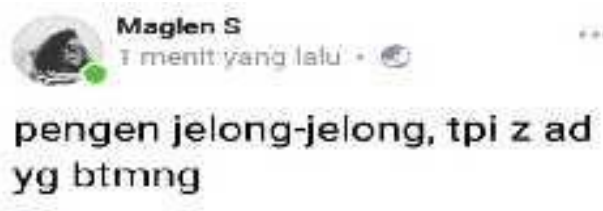

Data 02:

- ingin jalan-jalan, tapi tidak ada yang temani

Pada status tersebut terdapat kata jelong-jelong yang berasal dari kata jalan-jalan suku kata pertama huruf kedua diganti dengan huruf vokal /e/ dan suku kata kedua huruf kedua diganti dengan huruf vokal /o/ dan penambahan akhiran huruf vokal /g/. Fungsi dari kata jelong-jelong merupakan ajakan untuk berjalan-jalan. Kata ini sering digunakan oleh remaja dan pemuda Negeri Passo. 
Konteks: Peristiwa tutur yang disampaikan oleh Maglen $S$ saat penutur ingin jalan-jalan, tetapi tidak ada yang menemaninya.

Makna data prokem 02:Kata jelong-jelong yang artinya jalan-jalan dapat dimaknai yaitu bersenang-senang berjalan dengan melangkahkan kaki melihat pemandangan alam atau menonton pameran.

\section{Bahasa Gaul Bentuk Colloqial}

Colloqial adalah bahasa nonformal atau tidak resmi. Colloqial juga disebut sebagai bahasa sehari-hari. Ciri khas dari bahasa ini antara lain adalah dikuranginya pemakaian fitur-fitur linguistik seperti huruf dan pemenggalan suku kata yang terdapat dalam kata. Adapun data yang diperoleh dalam bentuk pemenggalan suku kata dalam kata seperti berikut.

Data 01: Data ini merupakan percakapan komentar ketika narasumber mengomentari status teman facebook-nya

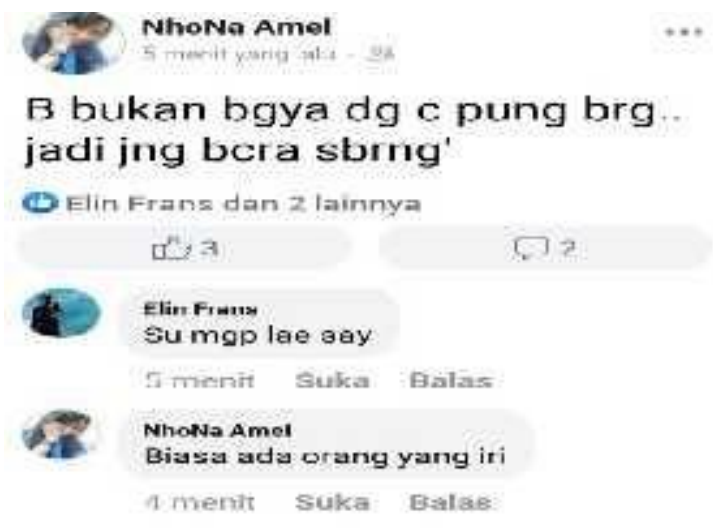

Status: NhoNa Amel: saya tidak bergaya dengan barang Anda jadi jangan berbicara sebarang, .

Elin Frans: sudah mengapa lagi sayang

NoNha Amel : biasa ada orang yang iri

Pada komentar di atas terdapat kata say yang berasal dari kata sayang, terdapat penghilangan suku kata kedua dan suku kata terakhir di kalangan remaja mereka lebih cenderung menggunakan kata say dari pada sayang agar penulisannya lebih pendek dan kata ini sering digunakan oleh remaja dan pemuda.

Konteks: Peristiwa tutur yang terjadi ketika Elin Frans mengomentari postingan status temannya yang iri kepada temannya dan kemudian direspon oleh temannya melalui akun facebook mereka masing-masing.

Makna data colloquial 01: Makna kata say yang berasal dari kata "sayang" yang memiliki makna rasa peduli kepada seseorang yang membuat sehingga hubungan mereka semakin dekat bisa sebagai sahabat, pacar, ortu dan sebagainya. 


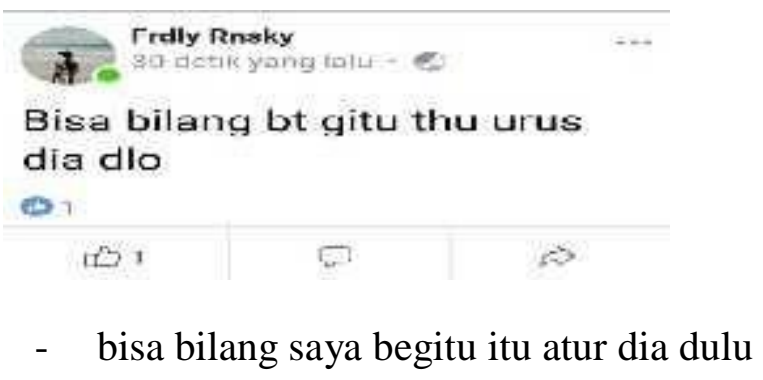

Pada status di atas terdapat kata gitu yang berasal dari kata begitu, ini terdapat penghilangan suku kata pertama. Fungsi kata ini agar terlihat lebih pendek, dan kata ini sering digunakan oleh kalangan remaja.

Konteks: Peristiwa tutur yang terjadi di facebook saat Fredly Rnsky sedang menyindir temannya.

Makna data colloqial 03: Dalam status tersebut terdapat kata gitu yang berasal dari kata "begitu" yang memiliki makna yang bertujuan untuk menjelaskan atau menyimpulkan sesuatu yang dibicarakan.

\section{KESIMPULAN}

Berdasarkan hasil temuan penelitian yang dilakukan di Passo, Kota Ambon maka ditemukan bahwa ragam bahasa gaul selalu berkembang dari waktu ke waktu berarti setiap tahun akan ada beberapa bahasa gaul yang akan dikembangkan dan digunakan oleh remaja. Tingkat pengguna di media facebook semakin meningkat sehingga cara pengucapan yang dituturkan akan semakin sederhana, cepat, dalam mengakses komunikasi yang dibutuhkan. Penggunaan bahasa gaul akan tumbuh berkembang bersamaan dengan perkembangan usia remaja.

Hasil temuan penelitian ini terbukti bahwa ditemukan ragam bahasa gaul di media sosial facebook dalam komunikasi tidak langsung yang dilakukan oleh remaja Negeri Passo, Kota Ambon yang berusia 14 sampai 19 tahun. Dalam situasi nonformal pada saat mempostingkan status atau mengomentari status teman-teman mereka lewat akun facebook pribadi mereka, ragam bahasa gaul yang peneiti kumpulkan dari bulan (AprilJuni 2018). Adapun data yang diperoleh sebagai berikut.

Ragam bahasa gaul berdasarkan bentunya yang digunakan untuk berkomunikasi di dalam media sosial facebook terdapat beberapa jenis seperti jargon yang merupakan kata dan akronim yang dipopulerkan oleh artis atau penyanyi. Ada juga prokem suatu bentuk bahasa gaul yang proses dalam pembentukanya dengan cara membalik susunan kata, memberi suatu sisipan, kata-kata yang diambil dari proses akronim dan singkatan, dan colloquial, yaitu penggunaan bahasa yang singkat sehingga berkurangnya fitur lingustik dalam kata tertentu. Sementara itu makna kosakata yang terdapat dalam media sosial facebook memiliki arti atau makna tertentu dikaji berdasarkan analisis sosiolingustik. 


\section{DAFTAR PUSTAKA}

Chaer, Abdul dan Agustina, Leonie, 2010. Sosiolinguistik Perkenalan Awal. Jakarta: Rineka Cipta.

Moleong, Lexy, J. 1990. Metodelogi Penelitian Kualitatif. Bandung: Remaja. 